\title{
Linking Foster Family Characteristics and Mental Health Symptoms of Youth in Care
}

\author{
Katie J. Stone $\mathbb{1}^{1} \cdot$ Yo Jackson ${ }^{2}$ \\ Accepted: 7 September 2021 / Published online: 22 September 2021 \\ (c) The Author(s), under exclusive licence to Springer Science+Business Media, LLC, part of Springer Nature 2021
}

\begin{abstract}
Youth in foster care are disproportionately at risk for developing internalizing and externalizing problems (Lawrence et al., 2006); however, a history of maltreatment prior to foster care placement does not automatically result in poor mental health outcomes. Among non-foster care youth, the quality of family interactions has been related to adjustment outcomes, such that low family cohesion and high family conflict is associated with poor mental health symptoms (Caples \& Barrera, 2006). While little is known about these constructs in foster care placements, they may help explain the variance in internalizing and externalizing problems for youth in foster care. The present study aimed to examine whether characteristics of the foster care environment (i.e., conflict, cohesion) across various placement types (i.e., traditional foster homes, group-care settings) could help explain the link between previous maltreatment exposure and mental health problems. The sample included 178 youth in foster care $\left(M_{\text {age }}=15.18, \mathrm{SD}=1.76\right)$ and their foster caregivers living in the Midwest. Youth participants completed self-report measures about prior maltreatment history, current family environment characteristics, and youth internalizing symptoms. Foster caregivers completed measures on current family environment and youth externalizing symptoms. Results indicated that caregiver report, but not youth report, of family cohesion was negatively associated with youth report of internalizing problems. When examining the indirect effects, youth report of family conflict partially accounted for the link between youth self-report of maltreatment and internalizing symptoms $(B=0.106,95 \% \mathrm{CI}=$ 0.026-0.186). Caregiver report of family conflict fully accounted for the association between youth self-report of maltreatment and caregiver report of youths' externalizing symptoms $(B=0.108,95 \% \mathrm{CI}=0.005-0.211)$. Findings highlight the importance of utilizing multiple informants when measuring foster family environment and suggest that family conflict is particularly salient for the mental health of youth in foster care.
\end{abstract}

Keywords Foster care $\cdot$ Family cohesion $\cdot$ Family conflict $\cdot$ Maltreatment chronicity $\cdot$ Mental health

\section{Highlights}

- Conflict within the foster care placement accounted for the association between maltreatment chronicity and youths' mental health outcomes.

- Foster caregivers and youth differed in their perceptions of conflict and cohesion within the foster care placement, and these discrepancies differentially impacted outcomes.

- Interventions aimed at improving the cohesion and conflict within foster placements may impact mental health outcomes for youth in foster care.

Katie J. Stone

Hoemb003@umn.edu

1 Clinical Behavioral Neuroscience, Masonic Institute for the Developing Brain, University of Minnesota Medical School, 717 Delaware Street SE, Minneapolis, MN 55414, USA

2 Department of Psychology, Associate Director of Child Maltreatment Solutions Network, The Pennsylvania State University, 140 Moore Building, University Park, PA 16801, USA
Youth in foster care are at a disproportionate risk for developing internalizing and externalizing problems compared to youth in the general population and youth with maltreatment histories who were not placed in foster care (Carbone et al., 2007; Lawrence et al., 2006). Although the association between past maltreatment and subsequent mental health problems has been well established (Rogosch et al., 2010; Tung et al., 2018), exposure to maltreatment 
does not automatically result in internalizing and externalizing symptoms. In fact, some youth exposed to maltreatment display few mental health problems (Oshri et al., 2017; Sasser et al., 2019). Variance in mental health outcomes of maltreatment exposed individuals may be partially explained by the quality of the foster family environment, given the literature indicating that low family cohesion and high family conflict are associated with worse adjustment outcomes in non-maltreated youth (Caples \& Barrera, 2006; Schleider \& Weisz, 2017). Although the research on foster family functioning is scant, the way caregivers and youth interact with each other is important for youth adjustment (Guzder et al., 2011). Additionally, differences in the measurement and conceptualization of maltreatment in previous studies may potentially explain mental health differences of youth in foster care. Due to the range in mental health concerns exhibited by youth in foster care and the impact of the caregiver-child

relationship on mental health outcomes (Bannink et al., 2013; Mills et al., 2013), the current study added to the field by examining how characteristics of the foster family environment across varying placement types (i.e., traditional foster homes; group-care settings) accounted for the link between maltreatment chronicity and youths' internalizing and externalizing problems.

\section{Conceptual Framework}

The present study was guided by social learning theory (Bandura, 1977) and the "cohesion-adaptability" framework of the Circumplex Model of Marital and Family Systems (Olson et al., 1983). According to social learning theory, emotional behaviors are learned through observing how others express their feelings and the consequences that occur due to these displays. Youths' observations of interactions among family members influence their use of similar strategies. Thus, youth who observe frequent conflict among caregivers (e.g., yelling, threats, physical aggression) may learn to use aggression as a method for resolving conflict. For the Circumplex Model, Olson et al. (1983) identified cohesion and adaptability as two fundamental dimensions necessary for family functioning. Family systems that are well-balanced in cohesion and adaptability will function more adequately, have appropriate communication skills, and have fewer problems than families that exhibit extreme levels on these dimensions. Cohesion involves the emotional bond between family members, whereas the adaptability dimension involves shifting of power structures, role relationships, and relationship rules over time (Olson et al., 1983). Well-functioning families exhibit moderate to high levels of cohesion (e.g., showing interest in other family members' activities; providing support to one another) and moderate levels of adaptability (e.g., increasing independence as children age; shifting responsibilities when a family member is ill). Although this model was not developed specifically for youth in foster care, previous studies have utilized this framework to guide research examining adaptability of foster and non-foster families during the COVID-19 pandemic (Bernedo et al., 2021) and comparing parent-child communication within foster, adoptive, and biological families (Rosnati et al., 2007). Thus, the Circumplex Model has been used to conceptualize the influence of family functioning characteristics (e.g., cohesion) within foster care samples. The present study is extending the use of this framework to foster care environments that include multiple placement types, such as traditional foster care homes and group-care settings. According to this theory, foster placements with moderate levels of cohesion and adaptability may provide the optimal functioning for youth in foster care.

\section{Maltreatment Chronicity}

Childhood maltreatment chronicity consists of persistent physical abuse, psychological abuse, sexual abuse and neglect over an extended period of time (English et al., 2005; Éthier et al., 2004; Graham et al., 2010), and it is associated with a variety of mental health problems (Jaffee, 2017). The risk for developing internalizing and externalizing symptoms may be higher for youth in foster care whose exposure to maltreatment has reached a level of severity requiring removal from their family of origin. However, evidence also suggests that some maltreated youth display few mental health problems (Oshri et al., 2017). While a number of factors may account for this multifinality, maltreatment chronicity is considered particularly relevant in explaining the variance in mental health outcomes (English et al., 2005; Hahm et al., 2010; JonsonReid et al., 2012). Youth with histories of maltreatment, especially those in foster care, experience a range of maltreatment types, and importantly, some variability in the frequency of abuse and neglect occurrences (Finkelhor et al., 2011; Hambrick et al., 2014). Results from a recent study of 272 youth in foster care showed that most participants experienced multiple types of maltreatment and multiple occurrences within each type and across types (Gusler \& Jackson, 2017). For example, 61\% of participants from the sample who reported on physical abuse endorsed experiencing 1-5 different events, 24.2\% endorsed 6-11 events, and $4.1 \%$ endorsed more than 11 events. In this study, similar percentage breakdowns were found for neglect exposure (i.e., experienced $1-5$ events = $54.4 \% ; 6-11$ events $=9.9 \% ; 11+$ events $=7 \%$ ), psychological/emotional abuse (i.e., $1-5$ events $=37.5 \% ; 6-11$ 
events $=40.5 \% ; 11+$ events $=14.1 \%$ ), and sexual abuse (i.e., $1-5$ events $=31.7 \%$; and $6+$ events $=8.3 \%$ ).

Research suggests that maltreatment chronicity can have a greater impact on mental health problems than a single event, regardless of the abuse type (Jonson-Reid et al., 2012; Miller et al., 2011). However, past studies rarely conceptualize maltreatment in a way that accounts for the chronicity and variability that exists for youth in foster care. Reducing youths' past exposure to a dichotomous variable (e.g., exposed to physical abuse or not) or a specific maltreatment type (e.g., only sampling sexually abused youth) provides an incomplete view of youths' experiences, namely exposure to multiple types of abuse and how often it occurred. In the current study, participants were asked to endorse any past or current exposure to maltreatment in order to calculate each youths' maltreatment chronicity. Participants who disclosed exposure to abuse in their current foster care placement were excluded from the present study $(n=12$; see methods section for more details). Importantly, the present study extends previous literature by examining how maltreatment chronicity is associated with current internalizing and externalizing symptoms among youth in foster care, and whether family environment constructs account for the variance in this association.

\section{Impact of Family Environment on Mental Health Problems in Biological Families}

Given that research on foster family functioning is limited, the current study was guided by theoretical frameworks and empirical literature developed with biological family samples. Consistent with social learning theory, high family conflict within biological families is associated with worse mental health symptoms for youth (Cummings et al., 2012; Lucia \& Breslau, 2006; Meyerson et al., 2002). For example, parent-child conflict was associated with youth conduct problems in a sample of adolescents without histories of maltreatment (Caples \& Barrera, 2006). Additionally, findings from a community-based prospective study identified links between conflict within the biological family and subsequent mental health outcomes (Cummings et al., 2012), such that marital conflict measured during kindergarten predicted children's emotional insecurity in second grade, which in turn predicted changes in internalizing and externalizing behaviors of participants in seventh grade. Further, Lucia and Breslau (2006) found that higher family conflict in biological families was associated with higher externalizing problems for youth in a five-year longitudinal study, suggesting that the degree of family conflict predicts mental health outcomes for youth. Finally, in a sample of adolescents with a history of maltreatment, high family conflict within the biological family was significantly associated with high levels of depression and psychological distress (Meyerson et al., 2002). Taken together, this literature suggests that the degree of conflict within a family environment can influence youths' internalizing and externalizing problems, and yet little is known about whether conflict in the foster care placement is associated with youth adjustment.

In line with the Circumplex Model, past studies have shown that higher levels of family cohesion in biological families are associated with lower levels of internalizing and externalizing problems in youth without maltreatment histories (Dale et al., 2011; Henneberger et al., 2016; Schleider \& Weisz, 2017). Dale et al. (2011) found that biological parents who reported higher levels of family cohesion also rated their children low on behavioral problems in comparison to parents who rated their children high in behavioral problems. In fact, a longitudinal study of children without histories of maltreatment, showed that higher levels of cohesion within their biological family at six years old were significantly associated with fewer internalizing problems five years later, whereas lower levels of family cohesion were associated with higher externalizing problems (Lucia \& Breslau, 2006). Furthermore, Reinherz et al. (2008) found similar trajectories in a sample of nonmaltreated adolescents, such that higher levels of family cohesion at age 15 predicted fewer externalizing behaviors at age 18. Interestingly, Owens et al. (2009) found that family cohesion within the biological family mediated the association between perceptions of interparental conflict and youths' internalizing and externalizing symptoms in a sample of low-income African American youth. In this study, interparental conflict negatively impacted family cohesion, which was associated with worse adjustment outcomes for youth. While interparental conflict among caregivers does not necessarily indicate exposure to child maltreatment, this study provides evidence that family cohesion accounts for some of the variance in adjustment outcomes of youth exposed to adversity within their biological families. Findings from this body of literature suggest that the degree of family cohesion likely accounts for some of the variance in youth adjustment. The present study aimed to replicate and build on results from Owen et al. (2009) by (1) examining similar family environment characteristics (e.g., family cohesion) for youth within foster placements (i.e., traditional foster homes; group-care settings), rather than biological family environments, and (2) examining the association between youth adjustment and a comprehensive measure of maltreatment exposure (i.e., maltreatment chronicity). Examining the role of cohesion and conflict within foster care placements may be particularly salient for youth in foster care who are at an increased risk of developing internalizing and externalizing problems. 


\section{Multiple Perceptions of Family Environment Characteristics}

Family members may view aspects of their family environment differently, and yet many of the past studies that have looked at associations between family environment and mental health outcomes have primarily utilized one reporter (e.g., parent-report; Caples \& Barrera, 2006; Meyerson et al., 2002). This limits our understanding of the constructs to one person's perspective. In fact, more recent work suggests that caregivers and youths often differ on their perceptions of family environment (De Los Reyes \& Ohannessian, 2016; Daches et al., 2018; Pérez et al., 2018), with caregivers reporting higher levels of cohesion than youth reporters (Pérez et al., 2018). A review of informant discrepancy indicates that low to moderate agreement between adolescent and parent reporters is typical, even when they "provide reports of family functioning domains that, by definition, occur within the same context of observation (i.e., the family unit)" (pp. 1959; De Los Reyes \& Ohannessian, 2016). Additionally, De Los Reyes (2011) notes, "there is no definitive way to determine who is an 'accurate' informant." While obtaining multiple informants is considered best practice for study designs (De Los Reyes \& Ohannessian, 2016), this may be particularly salient for a foster care sample, as youth and foster caregivers may not perceive their environments as similarly as other types of family units that are less transient. Furthermore, De Los Reyes et al. (2013) described how discrepancies between reporters can result in different outcomes, thus multiple informants are necessary to obtain a more comprehensive understanding of the role of family environment constructs in foster care placements. Therefore, the current study examined how youth and foster caregiver perceptions of these family environment characteristics within varying foster placements (i.e., traditional foster homes; group-care settings) were associated with maltreatment chronicity and youths' mental health symptoms.

\section{Foster Care Family Environments}

Research examining the quality of foster care placements is relatively limited, and yet extant literature with biological families suggest that family environment characteristics are significantly associated with mental health outcomes of youth with and without histories of maltreatment (Dale et al., 2011; Lucia \& Breslau, 2006; Meyerson et al., 2002). Given that environmental factors influence youth mental health outcomes, it is possible that high levels of cohesion and low levels of conflict within a foster care placement could mitigate the effects of maltreatment exposure on youth mental health outcomes. Furthermore, the present study sampled youth living in multiple placement types (i.e., traditional foster home, group-care settings). Traditional foster placements resemble more nuclear family environments (i.e., at least one consistent caregiver), whereas group-care placements include residential facilities and group home settings that have changing staff/caregivers and there are multiple foster youth living together. Little is known about how similar or dissimilar these placements are on environmental characteristics (i.e., cohesion, conflict) that are known to be related to mental health outcomes in youth. Due to the transitory nature of foster care, it is unclear whether characteristics of connectedness and conflict within the current foster placement are particularly important given that foster caregivers and youth are expected to eventually leave each other (e.g., reunification with biological parents; placement instability).

Few studies have examined how family functioning constructs within the foster care environment impact youth mental health symptoms, and none have examined the role of youths' maltreatment chronicity on this association. A recent study of youth in foster care found that higher levels of family conflict and lower levels of cohesion within the foster care placement were significantly associated with youth internalizing symptoms, but not externalizing symptoms (Stone et al., 2020); however, this study did not examine the role of maltreatment chronicity on these associations. Further, in a longitudinal study of youth adopted from foster care, family cohesion was not significantly associated with externalizing behaviors at baseline $(M=4$ years old), in the first 1-5 years post-adoption, or long-term follow up ( $M=19$ years old; Tung et al., 2018). These studies provide preliminary evidence of associations between foster family characteristics and youth adjustment outcomes. However, it remains unclear why family environment constructs are associated with externalizing symptoms in biological families, but similar links have not been found in these two studies of foster youth. Youth in foster care are at a particularly high risk for developing mental health problems (Lawrence et al., 2006), thus the current study aimed to expand on past literature to elucidate the variance in foster youths' mental health functioning by examining associations with maltreatment chronicity and family environment characteristics within various placement types in a robust sample of youth in foster care.

\section{Aims of the Current Study}

Past research has shown a link between maltreatment and mental health problems (Rogosch et al., 2010). Family environment constructs, such as low levels of family cohesion and high levels of family conflict, are linked to worsening symptoms (Dale et al., 2011; Lucia \& Breslau, 
2006). The current study adds to the literature by examining how youths' maltreatment history, namely maltreatment chronicity, and foster family environment characteristics may explain mental health outcomes in a sample of adolescents in varying foster care placements (i.e., traditional foster home; group-care settings). Further, youth and foster caregivers may not view their environments similarly. To address differences in perceptions, the present study assessed both youth and caregiver reports of family environment characteristics. The present study had the following aims: (1) to examine associations between maltreatment chronicity, family environment constructs, and youth-reported internalizing and caregiver-reported externalizing problems of youth in foster care, (2) to examine whether significant differences exist between youth and caregiver report of family cohesion and family conflict within different placement settings (i.e., traditional foster home vs. group-care placement), and (3) examine whether family environment constructs indirectly account for the association between maltreatment chronicity and youth mental health outcomes (i.e., separate path analyses were examined for adolescent report and caregiver report of family environment constructs). First, it was hypothesized that maltreatment chronicity and family conflict would be positively associated, and family cohesion would be negatively associated with mental health outcomes. Second, it was hypothesized that there would be no significant differences on key family environment variables between the placement types, but that youth and caregivers would endorse statistically significant differences, with caregivers reporting higher levels of cohesion and lower levels of conflict. Third, it was hypothesized that family conflict and family cohesion would indirectly account for the association between maltreatment chronicity and youth-reported internalizing and caregiver-reported externalizing symptoms.

\section{Methods}

\section{Participants}

The present study included 178 youth in foster care (47.8\% female) and their foster caregivers ( $84.7 \%$ female) living in a large metropolitan county in the Midwest. Youth ranged from 11 to 18 years old $(M=15.18$ years, $S D=1.76)$ and $45 \%$ of youth self-identified as African American, $36 \%$ as White, $9 \%$ as Multiracial, $5 \%$ as Latino or Hispanic, and 5\% as Other. The breakdown of race/ethnicity was consistent with the population of foster care in the recruitment area (Missouri Department of Social Services, 2016). Foster caregiver was defined as the individual who knows the child best within their current placement setting (i.e., foster parents, residential or group home staff member). The percentage of youth in residential care in the current sample is higher than national averages of youth in foster care (48.9\% living in foster homes, $51.1 \%$ living in residential facilities); however, it was comparable to past research that recruited older youth in foster care (i.e., $42 \%$ of youth in residential care; McCoy et al., 2008). The average number of placement moves was $10.03(S D=7.51)$ and the average length of time in care was 4.69 years $(S D=3.27)$. Regarding the education background of caregivers in the traditional foster home placements, $6.7 \%$ of foster caregivers had some high school, 20.9\% had graduated high school, $8.6 \%$ had graduated from trade school or community college, $27.6 \%$ had some college, $22.7 \%$ had graduated from college, $10.4 \%$ had completed graduate school, and $3.1 \%$ did not provide educational information. Among group-care caregivers, $19.3 \%$ had some college, $30.7 \%$ had graduated from college, $28.4 \%$ had completed graduate school, and $21.6 \%$ did not provide educational information. To be included in the study, youth were required to be in their current placement for at least 30 days. On average, youth were in their current placement for 9 months. Youth with a previous diagnosis of intellectual disability or autism spectrum disorder were excluded from the study due to the youth self-report nature of data collection.

\section{Procedures}

Participants were enrolled in the SPARK Project (Studying Pathways to Adjustment and Resilience in Kids), which is a federally funded, longitudinal research study designed to investigate factors that contribute to the association between maltreatment exposure and mental and physical health outcomes for youth in foster care. Foster youth were recruited from the designated county through a variety of methods, including attending social service agency sponsored events (e.g., foster parent training, support groups, educational events, case worker staff meetings), dissemination of flyers in foster care organization newsletters and via direct mailings or listservs, local news and radio broadcasts, and arranging informational meetings at residential centers that serve foster youth. Whenever a potential participant indicated interest, a member of the SPARK team called the family or group-care staff administrator to determine if the youth was eligible. Only youth and caregiver reports at Time 1 were included in the analyses. The university's Institutional Review Board and the state department of social services review board approved the SPARK Project. The state social service agency provided consent for youth participants. Caregivers were provided informed consent and youth were read an informed assent prior to participation.

Information on maltreatment, mental health, and family environment was provided by youth and caregivers via 
Table 1 Sources of data collection

\begin{tabular}{lll}
\hline Variable & Youth-report & Foster caregiver-report \\
\hline 1. Family conflict & $\checkmark$ & $\checkmark$ \\
2. Family cohesion & $\checkmark$ & $\checkmark$ \\
3. Maltreatment chronicity & $\checkmark$ & \\
4. Internalizing symptoms & $\checkmark$ & \\
5. Externalizing symptoms & & $\checkmark$ \\
\hline
\end{tabular}

surveys using an audio-computer assisted self-interview program. See Table 1 for information on source of data collection (i.e., youth-report vs. foster caregiver-report) for each construct examined in the present study. Graduate research assistants trained in clinical child psychology debriefed with each youth and adult participant after the questionnaires were administered in order to assess for mood changes, suicidal ideation, and current abuse. Study questions asked about past and current abuse; any report of abuse in the current foster home was reported to the state social service agency. Twelve youth reported current maltreatment and those individuals' data were removed from the present analyses. Participants were called within $48 \mathrm{~h}$ of questionnaire completion, to ensure that the youth experienced no ill effects of participation in the study. Both youth and caregivers received compensation in the form of a gift card. Additional information on the project methods, recruitment, data collection processes, and methods for confidentiality maintenance can be found in (Jackson et al., 2012).

\section{Measures}

\section{Family environment}

The Family Environment Scale was used to measure family environment via youth and foster caregiver report (FES; Moos \& Moos, 1994). This survey consists of ten subscales, but only the Cohesion (e.g., "There is a feeling of togetherness in our family;" "We really get along well with each other") and Conflict subscales (e.g., "We fight a lot in our family," "Family members sometimes hit each other") were used in the current study. The items on the Conflict and Cohesion subscale were the same for both caregiver and youth report. Scales consisted of nine true/false items, and the scores were summed. Higher values reflected more cohesion and worse conflict within the foster care placement. Prior to completing the questionnaire, caregivers and youth were instructed to answer each question based on the current foster care placement. According to Moos and Moos (1994), this measure demonstrates good overall reliability (i.e., Cohesion $\alpha=0.78$, Conflict $\alpha=0.75$ ) and validity. The FES Cohesion and Conflict scales were previously examined in a sample of youth in foster care, and it was found to be a valid and reliable measure (Stone et al., 2020). The present study utilized the same modified subscales as reported in the previous study.

\section{Mental health functioning}

Foster caregivers provided information on youths' externalizing symptoms via the Behavioral Assessment System Children-2 parent-report survey (BASC-2 PRS), whereas youth participants provided information on their own internalizing symptoms via the BASC-2 Self-Report of Personality (BASC-2 SRP). The Externalizing Problems domain score, which was completed by foster caregivers only, consisted of the hyperactivity, aggression, and conduct problem subscales (e.g., "Acts without thinking," "Argues when denied own way," "Gets in trouble;" Reynolds \& Kamphaus, 2004). Caregivers rated youth's externalizing behaviors on a 4-point Likert scale. The Internalizing Problems domain score, which was completed by youth participants only, consisted of the atypicality, locus of control, social stress, sense of inadequacy, anxiety, depression, and somatization subscales (e.g., "I am lonely," "Little things bother me," "I just don't care anymore"). Youth participants rated their internalizing symptoms via true/false and 4-point Likert scale questions. Consistent with past reviews on informant discrepancies in childhood psychopathology (De Los Reyes \& Kazdin, 2005), the caregiver participants in the current study reported on youths' externalizing behaviors as they may be more easily observed (e.g., aggression; arguing), whereas youth reported on their internalizing problems which may be less observable and require more inference (e.g., worry thoughts; feeling sad). For BASC-2 SRP, reliability coefficients are in the mid $0.90 \mathrm{~s}$ for the Internalizing Problems domain when computed by age group and gender (Tan, 2007). In the current study, alphas for the caregiver report of the BASC-2 PRS Externalizing Problems domain fell in the Excellent range $(\alpha=0.96)$ and the youth report of the BASC-2 SRP Internalizing Problems domain fell in the Excellent range $(\alpha=0.95)$. Higher scores indicate worse internalizing and externalizing problems. The BASC-2 PRS Externalizing scores ranged from 37 to 112 , with a mean of 71.43. Additionally, the BASC-2 SRP Internalizing scores ranged from 35 to 86 , with a mean of 56.52. Scores ranging from 60 to 69 are considered in the at-risk range and any scores of 70 or higher are considered clinical.

\section{Maltreatment history}

Lifetime history of maltreatment (including current maltreatment) was measured by youth self-report on the modified maltreatment classification system (MMCS; English \& 
LONGSCAN Investigators, 1997). The MMCS is often used to code child maltreatment in case files, but items were reworded to facilitate self-report assessment (e.g., the item "the child was hit or kicked in the face" was changed to "have you ever been hit or kicked in the face?"). Previous research has found that self-reported MMCS reliably identifies maltreatment chronicity among foster youth (Gabrielli et al., 2017).

Youth were asked if they had experienced any of the four types of maltreatment during the course of the individual's life and the frequency with which each endorsed event occurred: physical abuse (18 items; e.g., "in your lifetime, how often did someone kick or punch you?"), sexual abuse (12 items; e.g., "in your lifetime, how often has anyone forced you to look at their sexual parts?"), psychological abuse (26 items; e.g., "in your lifetime, how often has anyone ever blamed you for their own problems?"), and neglect (24 items; e.g., "in your lifetime, how often did your caregivers make sure you saw a doctor if you needed one?"). The frequency response options were $0=$ never occurred, $1=$ almost never occurred, $2=$ sometimes occurred, $3=$ often occurred, and $4=$ always occurred. Maltreatment chronicity was calculated by summing of the frequency items endorsed within each abuse type, and then calculating a total chronicity score by combining the chronicity totals across the four abuse categories. For example, if a youth reported that one physical abuse event occurred always (score of 4) and five physical abuse events occurred sometimes (score of 2), their chronicity score for physical abuse was 14 , which was combined with the chronicity scores for sexual abuse, psychological abuse, and neglect. Greater scores are indicative of worse maltreatment chronicity.

\section{Data Analyses Plan}

Consistent with Aim 1, correlation analyses were completed to examine the relation between family environment variables (i.e., family conflict; family cohesion), maltreatment chronicity, and youth mental health outcomes. For Aim 2, independent-samples t-tests were estimated to assess differences between family environment variables across multiple reporters and foster care placement types. Finally, for Aim 3, a path model was estimated using Mplus, version 7.4 statistical software (Muthén \& Muthén, 2010) to further understand the correlational associations and test the hypotheses that foster family environment (i.e., family cohesion, family conflict) accounted for the link between maltreatment chronicity and youth-reported internalizing and caregiver-reported externalizing symptoms. Age, gender, and placement type were examined as potential covariates given extant literature showing associations between these variables, maltreatment, and mental health problems
(Harpur et al., 2015; Maschi et al., 2008). Separate models were ran for caregiver report of family environment and youth report of family environment. More specifically, caregiver-reported externalizing problems and youthreported internalizing problems were simultaneously regressed on maltreatment chronicity, youth report of family cohesion, youth report of family conflict, placement type, age, and gender. Then, caregiver-reported externalizing problems and youth-reported internalizing problems were simultaneously regressed on maltreatment chronicity, caregiver report of family cohesion, caregiver report of family conflict, placement type, age, and gender. In the current study, there was minimal missing data $(6.7 \%)$. In light of the missing data, full information maximum likelihood estimation (FIML) was used to examine the proposed associations. FIML uses all available data to provide unbiased estimates of model parameters and has been shown to produce more reliable results than other missing data analysis strategies (Enders \& Bandalos, 2001). According to Graham (2009), FIML is considered an appropriate approach when missing data is less than $50 \%$ of the total data collected.

The bias-corrected bootstrap method was used to evaluate the proposed indirect effects of family environment (i.e., cohesion and conflict). Past literature has shown that this approach provides a more accurate balance between Type 1 and Type 2 errors than alternative methods such as Sobel's (MacKinnon et al., 2004). Examination of the proposed hypotheses for Aim 3 yielded a fully saturated model (i.e., a model with zero degrees of freedom), providing the most stringent test of indirect effects. Fully saturated models will always produce a perfect fit for the data; therefore, model fit indices were not reported (Kline, 2011).

\section{Results}

\section{Descriptive Statistics (Aim 1)}

Table 2 presents the means, standard deviations, and bivariate correlations describing associations among study variables. As expected, maltreatment chronicity had a small to moderate positive association with youth report of internalizing problems, and youth and foster caregiver report of family conflict, but a small negative association with youth and foster caregiver report of family cohesion. Maltreatment was not significantly correlated with caregiver-reported externalizing problems. Caregiver endorsed externalizing problems showed small to moderate positive associations with youth report of internalizing problems, and youth and foster caregiver report of family conflict, but a small negative association with foster 
Table 2 Correlations, means, and standard deviations of study variables $(N=178)$

\begin{tabular}{|c|c|c|c|c|c|c|c|c|c|c|c|c|}
\hline Variable & 1 & 2 & 3 & 4 & 5 & 6 & 7 & 8 & 9 & 10 & 11 & 12 \\
\hline 1. Age & - & & & & & & & & & & & \\
\hline 2. Gender & -0.135 & - & & & & & & & & & & \\
\hline 3. Placement type & -0.012 & $0.243^{* *}$ & - & & & & & & & & & \\
\hline 4. Race/Ethnicity & -0.098 & 0.019 & -0.110 & - & & & & & & & & \\
\hline 5. Length of time in care & $0.167^{*}$ & 0.019 & 0.019 & $-0.150^{*}$ & - & & & & & & & \\
\hline $\begin{array}{l}\text { 6. Maltreatment chronicity } \\
\text { (youth-report) }\end{array}$ & 0.104 & $-0.238^{* *}$ & 0.038 & $0.195^{*}$ & -0.133 & - & & & & & & \\
\hline 7. Cohesion (youth-report) & -0.066 & 0.044 & -0.133 & -0.067 & 0.008 & $-0.227^{* *}$ & - & & & & & \\
\hline 8. Conflict (youth-report) & 0.022 & 0.009 & $0.207^{* *}$ & 0.014 & -0.084 & $0.334^{* *}$ & $-0.609^{* *}$ & - & & & & \\
\hline $\begin{array}{l}\text { 9. Cohesion (caregiver- } \\
\text { report) }\end{array}$ & -0.091 & -0.093 & $-0.194^{* *}$ & -0.093 & 0.132 & $-0.163^{*}$ & 0.105 & -0.143 & - & & & \\
\hline $\begin{array}{l}\text { 10. Conflict (caregiver- } \\
\text { report) }\end{array}$ & -0.010 & $0.153^{*}$ & $0.356^{* *}$ & -0.018 & -0.016 & $0.200^{*}$ & $-0.167^{*}$ & $0.223^{* *}$ & $-0.562^{* *}$ & - & & \\
\hline $\begin{array}{l}\text { 11. Externalizing } \\
\text { Problems (caregiver- } \\
\text { report) }\end{array}$ & -0.018 & 0.088 & $0.261^{* *}$ & -0.056 & 0.097 & 0.025 & -0.146 & $0.242^{* *}$ & $-0.223^{* *}$ & $0.424^{* *}$ & - & \\
\hline $\begin{array}{l}\text { 12. Internalizing Problems } \\
\text { (youth-report) }\end{array}$ & 0.104 & $-0.152^{*}$ & $0.176^{*}$ & 0.068 & $-0.192^{*}$ & $0.370^{* *}$ & $-0.322^{* *}$ & $0.461^{* *}$ & $-0.267^{* *}$ & $0.205^{* *}$ & $0.160^{*}$ & \\
\hline Mean & 15.18 & - & - & - & 4.22 & 19.41 & 4.47 & 2.94 & 5.64 & 3.54 & 71.43 & 56.52 \\
\hline Standard Deviations & 1.76 & - & - & - & 4.62 & 11.90 & 1.58 & 2.07 & 1.38 & 2.67 & 15.63 & 11.01 \\
\hline
\end{tabular}

${ }^{*} p<0.05,{ }^{* *} p<0.01,{ }^{* * *} p<0.001$, Gender (Female 0, Male 1), Placement type (Group-care 0; Traditional foster care home 1), Race/Ethnicity (Asian 1, American Indian 2, African American 3, Hispanic 4, Native Hawaiian 5, Caucasian 6, Multiracial 7, Other 8)

caregiver report of family cohesion. Caregiver-reported externalizing problems was not significantly correlated with youth report of family cohesion. Youths' report of internalizing problems indicated a small to moderate negative correlation with youth and foster caregiver report of family cohesion, but a small to moderate positive association with youth and foster caregiver report of family conflict. Length of time in foster care had a small positive correlation with age and a small negative correlation with ethnicity and youth-reported internalizing problems.

\section{Informant Discrepancies on Family Environment (Aim 2)}

A paired sample $t$-test was conducted to compare family cohesion of youth report and foster caregiver report within the entire sample. There was a significant difference in scores between youth $(M=2.95, \mathrm{SD}=2.07)$ and foster caregiver $(M=3.55, \quad \mathrm{SD}=2.67) ; \quad t(168)=-2.62, \quad p=$ 0.010 . Additionally, there was a significant difference in family conflict scores for youth $(M=4.45, \mathrm{SD}=1.58)$ and foster caregiver report $(M=5.64, \quad \mathrm{SD}=1.39)$; $t(169)=-7.735, p=0.000$.

A paired sample t-test was conducted to compare family environment variables of each reporter across the different placement types (i.e., traditional foster care home; groupcare setting). For youth report of family cohesion, there was no statistically significant difference between traditional foster homes $(M=4.65, \mathrm{SD}=1.56)$ and group-care settings $(M=4.28, \mathrm{SD}=1.58 ; t(169)=1.57, p=0.117)$. For youth report of family conflict, there was a significant difference between traditional foster homes $(M=2.44, \mathrm{SD}=2.10)$ and group-care placements $(M=3.44, \mathrm{SD}=1.92 ; t(168)=$ $-3.24, p=0.001$ ), with youth in traditional foster placements endorsing lower levels of conflict. Regarding foster caregiver report of family cohesion, there was a significant difference between traditional foster homes $(M=5.99$, $\mathrm{SD}=1.10)$ and group-care settings $(M=5.30, \mathrm{SD}=1.53$; $t(174)=3.41, p=0.001)$, with caregivers in traditional foster placements reporting higher scores for cohesion. Finally, there was a significant difference in foster caregiver report of family conflict between traditional foster homes $(M=2.34, \mathrm{SD}=2.43)$ and group-care placements $(M=$ $4.69, \mathrm{SD}=2.36 ; t(174)=-6.50, \quad p<0.000)$, such that caregivers in group-care settings endorsed higher levels of conflict.

\section{Path Analysis (Aim 3)}

For the adolescent model, an indirect path model was estimated to evaluate whether youth report of family cohesion and youth report of family conflict accounted for the link between maltreatment chronicity and youth-reported internalizing and caregiver report of externalizing symptoms 

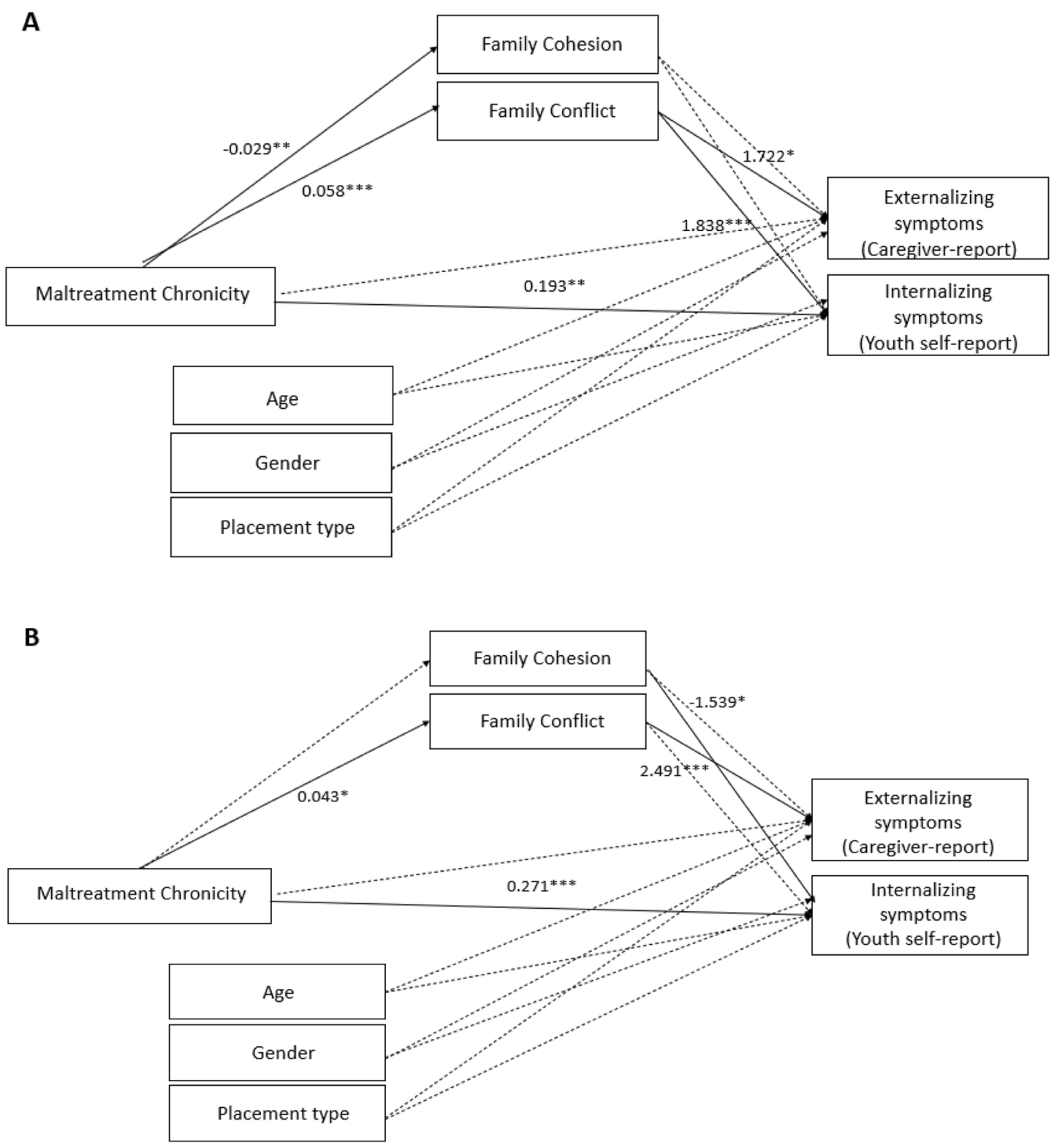

Fig. 1 Panel A depicts the associations between adolescent report of family conflict, adolescent report of family cohesion, maltreatment chronicity, and study covariates (i.e., age, gender, placement type) and the mental health outcomes (i.e., internalizing and externalizing symptoms), as well as the partial indirect effects of family conflict accounting for the association between maltreatment chronicity and internalizing symptoms. Panel B depicts the direct associations caregiver report of family conflict, caregiver report of family cohesion, maltreatment chronicity, and study covariates (i.e., age, gender, placement type) have with internalizing and externalizing, as well as the indirect effects of family conflict accounting for the association between maltreatment chronicity and internalizing symptoms. Solid arrows indicated significant pathways. Dotted arrows indicate nonsignificant pathways. ${ }^{*} p<0.05,{ }^{* *} p<0.01,{ }^{* * *} p<0.001$.
(Fig. 1, Panel A). The results indicated higher levels of family conflict was positively associated with caregiverreported externalizing problems $(\beta=1.722, p=0.025)$. Additionally, higher levels of family conflict $(\beta=1.838$, $p=0.001)$ and maltreatment chronicity $(\beta=0.193, p=$ 0.006) were positively associated with youth-reported internalizing symptoms. Maltreatment chronicity was positively associated with family conflict $(\beta=0.058, p<0.000)$, but negatively associated with family cohesion $(\beta=-0.029$, $p=0.011)$. Results from the path models suggest that the main effect for placement type was not significantly associated with internalizing $(\beta=0.53, p=0.515)$ or externalizing symptoms $(\beta=1.98, p=0.109)$ for the adolescent model. The bias corrected bootstrap test of the indirect effects revealed that youth report of family conflict partially accounted from the association between maltreatment chronicity and youths' internalizing symptoms $(B=0.106$, $95 \% \mathrm{CI}=0.026-0.186)$. 
A second indirect path model was estimated to evaluate whether foster caregiver report of family cohesion and family conflict accounted for the link between maltreatment chronicity and youth-reported internalizing and caregiverreported externalizing symptoms (Fig. 1, Panel B). The results indicated that family conflict was positively associated with caregiver report of externalizing problems $(\beta=$ $2.491, p<0.000$ ). Additionally, maltreatment chronicity was positively associated with youth report of internalizing symptoms $(\beta=0.271, p<0.000)$, whereas family cohesion was negatively associated $(\beta=-1.539, p=0.022)$. Finally, maltreatment chronicity was positively associated with family conflict $(\beta=0.043, p=0.019)$. Placement type was not significantly associated with internalizing symptoms $(\beta=0.767, p=0.400)$ or externalizing symptoms $(\beta=$ $0.998, p=0.366)$. The bias corrected bootstrap test of the indirect effects revealed that foster caregiver report of family conflict fully accounted from the associations between maltreatment chronicity and caregiver-reported externalizing symptoms $(B=0.108, \quad 95 \% \quad \mathrm{CI}=$ $0.005-0.211)$. Length of time in foster care was added as covariate to both models. The construct was nonsignificant; thus, this variable was removed for reasons of parsimony.

\section{Discussion}

Extant literature suggests an association between maltreatment and mental health outcomes for youth in foster care (Rogosch et al., 2010); and yet, some youth exposed to maltreatment display few adjustment difficulties (Oshri et al., 2017). Family environment constructs may help explain the differences in mental health outcomes among youth. Low family cohesion and high levels of family conflict have been associated with poorer adjustment outcomes in samples of non-maltreated youth (Caples \& Barrera, 2006; Dale et al., 2011) and for maltreated youth who were not in foster care (Meyerson et al., 2002). Further, initial studies with foster care samples provide preliminary evidence of this association (Stone et al., 2020; Tung et al., 2018). The present study extended past research by examining whether youth and caregiver report of foster environment characteristics (i.e., cohesion and conflict) across multiple placement types (i.e., traditional foster home; group-care placement) significantly accounted for the relation between youths' history of maltreatment chronicity and current mental health symptoms (Aims 1, 3). Further, the present study examined potential differences in perceptions among reporters across placement types (Aim 2). Results from the current study indicate that youth and caregiver report of conflict and cohesion differentially associate with outcomes, and that family conflict appears to account for the association between maltreatment chronicity and mental health problems. These findings have important clinical considerations for youth in foster care and offer opportunities for future directions.

Consistent with predictions for Aim 1, youth and caregiver report of family conflict was positively correlated with youth report of internalizing and caregiver report of externalizing problems, whereas family cohesion was negatively correlated with mental health outcomes. Interestingly, maltreatment chronicity was positively correlated with youth-reported internalizing symptoms, but not significantly associated with caregiver-reported externalizing symptoms.

\section{Informant Discrepancies on Family Environment Constructs}

Research suggests that caregivers and youth offer different perspectives on characteristics from the family environment (De Los Reyes \& Ohannessian, 2016; Daches et al., 2018), with caregivers reporting higher levels of cohesion than youth reporters (Pérez et al., 2018). Consistent with predictions for Aim 2 and in line with past literature, the results from the current study indicate that youths and caregivers endorsed statistically different scores for family cohesion, with caregivers reporting higher scores on cohesion than youth. For family conflict, youth and caregiver scores were significantly different, with caregivers endorsing higher levels of conflict, which was inconsistent with the predictions. Despite respondents providing reports of these constructs from the same context, past research suggests that there may be differences in scores when using multiple reporters (De Los Reyes \& Ohannessian, 2016), which often lead to variations in outcomes (De Los Reyes et al., 2013). These results suggest that both caregivers and youth should be asked about their perceptions of family cohesion and conflict in order to assess how these constructs are uniquely related to past maltreatment exposure and current mental health functioning depending on the informant.

The present sample included adolescents living in different placement types (i.e., traditional foster home; groupcare placement), so the family environment variables of each reporter were compared across placement type. Consistent with predictions, there were no significant differences on youth report of family cohesion, which suggests that youth are viewing similar levels of cohesion in traditional foster placements and in group-care settings. However, results also showed that there were statistically significant differences between placement types on youth report of conflict, caregiver report of cohesion, and caregiver report of conflict. While the difference in mean scores for family environment constructs were not sufficient to detect significantly different outcomes, traditional foster homes are considered structurally different from group-care 
placements. For example, the number of caregivers in a group-care setting is higher than a traditional foster care home, which may lead to higher levels of conflict and lower levels of cohesion given the variability in personality, temperament, interests, and expectations among the rotating staff within a group-care setting. Although variability may also exist among caregivers in a traditional foster home (e.g., foster youth conflicting with one adult more than the other), the number of caregivers that youth have to engage with is greater in group-care settings. In addition to interacting with rotating staff members, residential care settings often have difficulties retaining staff, typically due to 'emotional exhaustion,' dealing with challenging behaviors, and concerns of safety (Colton \& Roberts, 2006). These factors can lead to strains on youth and caregiver interactions and the overall functioning of the foster care placement. Thus, the present study contributes to the literature base by examining both foster youth and caregiver report of conflict and cohesion within varying foster care settings.

Due to the statistically significant differences between reporters on key family environment variables, placement type was added into the path models as a covariate, in order to account for the variance in mental health outcomes due to differences in placement type within the sample. Results indicated that placement type was not statistically associated with youth-reported internalizing symptoms or caregiver report of externalizing problems, suggesting that placement within a specific setting did not independently account for mental health outcomes. Adolescents in foster care are often disproportionally placed in group-care settings (McCoy et al., 2008), so analyzing these constructs with a sample of youth living in multiple foster care settings, including group-care, was crucial. Future studies should consider examining other factors relevant to the different foster care placement types, which may further explain the mental health outcomes for youth in foster care.

\section{Path Models: Main Effects and Indirect Associations}

In examining how family environment characteristics account for the association between maltreatment chronicity and mental health outcomes (Aim 3), many of the hypothesized links were statistically significant. Findings are organized by independent variable in order to discuss how associations compare across reporters and dependent variables.

\section{Maltreatment Chronicity}

As predicted, results indicate that maltreatment chronicity was significantly associated with youths' self-reported internalizing symptoms. This finding adds to the known literature that demonstrates the adverse effects of childhood maltreatment on youths' internalizing symptoms (Lawrence et al., 2006). For youth who experience repeated and frequent exposure to maltreatment (i.e., maltreatment chronicity), there may be minimal opportunities for youth to learn appropriate strategies for managing their emotions, thereby increasing the risk for psychological distress and internalizing problems (De Young et al., 2011; Moriguchi et al., 2006).

Surprisingly, maltreatment chronicity was not significantly associated with caregiver-reported externalizing problems. Previous literature certainly suggests a relation between maltreatment and youth externalizing problems (Mills et al., 2013). However, prevalence rates of externalizing symptoms for youth in foster care range between 20 and $40 \%$, which suggests that not all youth demonstrate externalizing symptoms (Simmel et al., 2001; Vanschoonlandt et al., 2013). Given that youth reported on maltreatment chronicity and the foster caregiver reported on externalizing problems, it is possible that the nonsignificant association is due to having different informants. This explanation also supports the justification to use multiple informants, as findings may differ based on the method of measurement (i.e., perception of reporter). These results suggest that other variables may better explain the variance in youth externalizing problems.

\section{Family cohesion}

Results suggested that maltreatment chronicity was negatively associated with youth report of family cohesion, but not caregiver report of family cohesion. These findings are consistent with previous literature that examined the association in biological families of youth exposed to maltreatment (Stith et al., 2009). Findings from the current study provide new evidence that extends this association to a foster care sample, suggesting that a history of maltreatment chronicity is associated with youths' negative perceptions of cohesion within their current foster care placement. Consistent with the cohesion-adaptability framework, the biological family environments of foster care youth may fall closer to the chaotic end of the adaptability dimension, and the new foster family environments may be starkly different than their biological home environments. Due to changes in role relationships, rules, and power structures of the new foster placements, it is possible that youth with the highest levels of maltreatment chronicity may perceive interactions with current foster families as disconnected. Additionally, maltreatment chronicity was only associated with youth report, and not caregiver report, of family cohesion. In line with social learning theory, it is possible that past exposure has altered youths' perception of interactions among family members, such that the foster care environment may be viewed as less cohesive by youth. 
Thus, youth exposed to maltreatment may be more attuned to negative interactions among foster family members.

As expected, results indicated that caregiver report of family cohesion was negatively associated with youthreported internalizing symptoms. These results are consistent with recent literature on youth in foster care, which also suggests that lower levels of family cohesion are associated with higher internalizing symptoms in youth (Stone et al., 2020). The findings are consistent with the cohesionadaptability framework (Olson et al., 1983), which suggests that families with low levels of cohesion tend to have children with poor adjustment outcomes, such as internalizing symptoms. Interestingly, it was the caregiver report, and not the youth report, of cohesion that was significantly associated with youth report of internalizing symptoms. It is possible that there may be overlapping features between lack of cohesion and internalizing symptoms, and the informants are inferring different meanings to similar observed behaviors. For example, youths' expression of internalizing symptoms (e.g., withdrawn and isolative) may be interpreted as less family cohesion by the caregiver, whereas the adolescent may interpret this behavior as depression or anxiety symptoms. This may explain why youth report of family cohesion was not significantly associated with youthreported internalizing symptoms. The sampling of multiple reporters allows for discrepancies in the outcomes and varying perceptions of the behaviors being measured.

Inconsistent with predictions, caregiver and youth report of family cohesion were not associated with caregiverreported externalizing problems. Additionally, family cohesion did not indirectly account for the association between maltreatment chronicity and mental health outcomes. Past literature with biological families certainly suggests an association between high levels of family cohesion and low levels of behavior problems (Dale et al., 2011; Schleider \& Weisz, 2017), but the current findings suggest this may not be the case in the foster family context. Findings from the current study are consistent with results from past studies of youth in foster care (Stone et al., 2020; Tung et al., 2018), which also found that family cohesion was not related to externalizing problems. It is possible that mechanisms of cohesion may be less salient for youth behavior problems when caregiver-child relationships are new and expected to be temporary. These nonsignificant findings suggest that the degree of connectedness and unity one feels within a foster care placement may not influence youth externalizing problems.

\section{Family conflict}

Maltreatment chronicity was positively associated with youth and caregiver report of family conflict, which is consistent with past studies on biological families of maltreated youth (Herrenkohl \& Herrenkohl, 2007; Stith et al., 2009). In a meta-analysis of 155 studies examining the risk factors associated with child abuse, Stith et al. (2009) found a large effect size for the relation between physical abuse and high family conflict. Results from the present study provide first-time evidence of this association within the context of the foster care placement. Although the present analyses are from cross-sectional data, the findings suggest that previous maltreatment may impact the perception of family conflict in a current foster placement. Although not directly tested, social learning theory suggests that youths who experienced significant conflict in their biological family may then interact with foster family members in a similar manner to their families of origin.

In addition, youth and caregiver report of family conflict were positively associated with caregiver report of externalizing symptoms. These results are consistent with extant literature suggesting a link between family conflict and externalizing problems for youth with and without histories of maltreatment exposure (Caples \& Barrera, 2006; Cummings et al., 2012; Lucia \& Breslau, 2006). Additionally, youth report of family conflict was positively associated with youths' self-report of internalizing symptoms. Again, past studies of youth with histories of maltreatment support these findings (Meyerson et al., 2002; Stone et al., 2020). Results from the current study not only confirm previous literature, but findings also provide evidence of this association within a sample of adolescents in foster care.

Consistent with predictions and extending the previous literature, the results indicated that caregiver report of family conflict fully accounted for the link between maltreatment chronicity and caregiver-reported externalizing symptoms. Having a history of repeated and ongoing exposure to maltreatment may lead to feelings of threat or difficulties when confronted with conflict (Grych et al., 2002), which can lead to behavioral dysregulation (i.e., externalizing behaviors; Schermerhorn et al., 2007). Furthermore, social learning theory suggests that youth may have learned ineffective strategies for resolving distress through the modeling of emotion dysregulation and externalizing behaviors by maltreating caregivers. These learned behaviors may have influenced the interactions youth have with foster caregivers in their current placements, and in turn further contribute to externalizing problems.

Additionally, findings from the current study indicate that youth report of family conflict partially accounted for the link between maltreatment chronicity and youth report of internalizing symptoms. Although maltreatment is strongly linked to youth internalizing symptoms, this finding extends previous literature by identifying family conflict as a mechanism that partially accounts for this link. It is possible that repeated exposure to maltreatment can often lead to biological caregivers' failure to attend to the 
emotional needs of the child. In these environments, children may learn that emotional expression is unaccepted, ignored, or invalidated (Paivio \& McCulloch, 2004). To adapt to such environments, children may withdraw and/or suppress emotional expression. Therefore, when placed in a new family environment that is perceived as high in conflict, youth may resort to learned maladaptive coping strategies for managing their emotions, thus leading to worsening internalizing symptomatology.

\section{Clinical Considerations}

Given the role of family conflict as a mechanism linking maltreatment chronicity to current mental health outcomes, intervention and prevention efforts targeting the foster family environment may help to minimize mental health symptoms for youth in foster care. Youth may have learned strategies in their previous maltreating environments, which could be contributing to the conflict within their current foster care placement. Additionally, because foster caregivers and youth may view their relationships as transient, there may be less motivation to work together to resolve issues. Social service agencies have an obligation to keep foster youth physically safe, but there are minimal regulations regarding the youths' mental health. Evidencebased interventions focused on fostering relationships and conflict resolution may reduce conflict within the foster care placement, which was associated with youth-reported internalizing and caregiver-reported externalizing problems. Some of the interventions that strengthen relationships, promote family functioning, and address conflict resolution strategies include Collaborative Problem Solving (Pollastri et al., 2013) and Multisystemic Family Therapy (LaFavor \& Randall, 2013). Evidence-based interventions that focus on family dynamics within the foster care unit may improve mental health symptoms. In conjunction with family-based and parent-adolescent interventions, youth in foster care may also benefit from individualized treatments that focus on developing adaptive coping strategies and cognitive restructuring of maladaptive thought patterns, such as Cognitive Behavioral Therapy (Hofmann et al., 2012), or interventions focused on processing their trauma exposure, such as Trauma-Focused Cognitive Behavioral Therapy (de Arellano et al., 2014). Given these findings and the rich evidence base for interventions aimed at mitigating mental health symptoms, foster caregivers and social service agencies should assess for youths' symptoms and initiate intervention services when needed. Furthermore, social service agencies are encouraged to consider whether foster caregivers are prepared for the challenges of having an adolescent with extensive maltreatment exposure. Social service agencies should ensure that foster caregivers are well trained on how to manage conflict that arises, how to foster cohesion within the placement setting, and how to identify warning signs for significant mental health concerns.

\section{Limitations and Conclusions}

The results of the current study should be interpreted within the context of several limitations. First, the cross-sectional design of the study limits the ability to make inferences about directionality. Longitudinal designs are necessary to determine the direction of causality. Second, the conceptual framework guiding the present study, Olson et al. (1983)'s Circumplex Model, was not initially developed for foster home placements. Although it is been adapted for foster care samples, it may not account for the nuanced and complex characteristics of multiple foster care placements settings. Third, assessment of the family environment included both youth and caregiver report, however the length of time in the current placement was variable $(M=$ 9 months), thus it is possible that youth who lived in their current placement for a shorter period of time may have had a less clear sense of the qualities of their new placement environments compared to youth who had lived several months or years in their current placement. The FES was designed for biological families where there are no expectations for minimal amount of time spent together. Therefore, it is hard to determine the appropriate amount of contact required by family members before completing the FES for youth in foster care. Given the unique dynamics that exist within foster care placements, examining cohesion and conflict via the FES may not have fully captured these constructs. Despite the challenges with the FES measure, it was imperative to use a validated and recognized measure in order to compare findings across studies. Fourth, the present study used a variety of approaches to recruit participants. Any foster youth who expressed interest and met eligibility requirements were enrolled in the study. Therefore, the sample is reflective of the foster youth who were available to participate in the project, which may limit the generalizability of the results. Given the importance of understanding these constructs within this population, traditional random sampling methods were not possible. Finally, it is also possible that the youth had externalizing and internalizing symptoms prior to placement in foster care, which may have influenced their current functioning. Additionally, the current study did not measure the length of time in prior placements or youths' perceptions of previous placements, which may have influenced their views of cohesion and conflict in the current placement setting. Thus, prior mental health problems and experiences from their family of origin or past foster placements could have influenced scores related to their current functioning. 
Despite these limitations, the current findings expand the literature in a number of ways. First, the present study utilized a robust measurement of maltreatment history (i.e., maltreatment chronicity), which accounts for multiple types of abuse and the occurrence of each type among participants. Second, the current study examined how foster family environment characteristics (i.e., cohesion, conflict) accounted for the relation between maltreatment chronicity and mental health. Finally, multiple informants of family environment variables were assessed in order to account for differing perceptions. Findings from the current study indicate that foster care family characteristics account for the variance in mental health outcomes, with family conflict serving as a mechanism relevant to the development of both externalizing and internalizing symptoms. Thus, this study suggests that the quality of the foster care placement is an important factor that influences mental health outcomes for youth in foster care.

\section{Future Directions}

Given the new findings regarding family conflict and cohesion influencing both internalizing and externalizing symptoms of youth in foster care, several directions for additional investigations are warranted. Future research should investigate these variables in a prospective longitudinal study to determine if foster family characteristics predict mental health outcomes or if youth pathology influences family dynamics. Future studies may benefit from having additional respondents, such as case workers, biological caregivers, or teachers, who could provide their unique perspectives on youths' maltreatment history and mental health functioning. Furthermore, it is possible that other constructs may operate as mediating and moderating factors in explaining the propensity of mental health outcomes for foster care youth. Thus, researchers should examine the contribution of additional constructs known to impact youth adjustment, such as the degree of security youth feel in their current placement and perceptions of family environments in prior placements. Finally, future studies should examine intervention and prevention strategies for conflict within the foster care placement, given that it accounts for the link between maltreatment and youth mental health outcomes.

Acknowledgements This research was supported by funding from the National Institutes of Mental Health, RO1 Grant MH079252-03. The writing of this manuscript was supported in part by the National Science Foundation Graduate Research Fellowship Program under Grant No. DGE-1540502 awarded to K.J. Stone. Any opinions, findings, and conclusions or recommendations expressed in this material are those of the author(s) and do not necessarily reflect the views of the National Science Foundation.

\section{Compliance with Ethical Standards}

Conflict of Interest The authors declare no competing interests.

Ethical Approval All procedures performed in studies involving human participants were in accordance with the ethical standards of the institutional and/or national research committee and with the 1964 Helsinki declaration and its later amendments or comparable ethical standards. This article does not contain any studies with animals performed by any of the authors.

Informed Consent Informed consent was obtained from all individual participants included in the study.

Publisher's note Springer Nature remains neutral with regard to jurisdictional claims in published maps and institutional affiliations.

\section{References}

de Arellano, M. A., Lyman, D. R., Jobe-Shields, L., George, P., Dougherty, R. H., Daniels, A. S., \& Delphin Rittmon, M. E. (2014). Trauma-focused cognitive-behavioral therapy for children and adolescents: Assessing the evidence. Psychiatric services, 65(5), 591-602. https://doi.org/10.1176/appi.ps.201300255.

Bandura, A. (1977). Social learning theory. Englewood Cliffs, NJ: Prentice Hall.

Bannink, R., Broeren, S., van de Looij-Jansen, P. M., \& Raat, H. (2013). Associations between parent-adolescent attachment relationship quality, negative life events and mental health. PLoS ONE, 8(11), 1-7. https://doi.org/10.1371/journal.pone.0080812.

Bernedo, I. M., Oliver, J., Urbano-Contreras, A., González-Pasarín, L. (2021). Perceived stress, resources and adaptation in relation to the COVID-19 lockdown in Spanish foster and non-foster families. Child and Family Social Work. https://doi.org/10. $1111 / \mathrm{cfs} .12871$.

Caples, H. S., \& Barrera, Jr, M. (2006). Conflict, support, and coping as mediators of the relation between degrading parenting and adolescent adjustment. Journal of Youth and Adolescence, 35(4), 603-615. https://doi.org/10.1007/s10964-006-9057-2.

Carbone, J. A., Sawyer, M. G., Searle, A. K. \& Robinson, P. J. (2007). The health-related quality of life of children andadolescents in home-based foster care. Quality of Life Research, 16, 1157-1166. https://doi.org/10.1007/s11136-007-9227-z.

Colton, M. \& Roberts, S. (2006). Factors that contribute to high turnover among residential child care staff. Child \& Family Social Work, 12, 133-142. https://doi.org/10.1111/j.1365-2206. 2006.00451.x.

Cummings, E. M., George, M. R. W., McCoy, K. P., \& Davies, P. T. (2012). Interparental conflict in kindergarten and adolescent adjustment: Prospective investigation of emotional security as an explanatory mechanism. Child Development, 83(5), 1703-1715. https://doi.org/10.1111/j.1467-8624.2012.01807.x.

Daches, S., Vine, V., Layendecker, K. M., George, C. J., \& Kovacs, M. (2018). Family functioning as perceived by parents and young offspring at high and low risk for depression. Journal of Affective Disorders, 226, 355-360. https://doi.org/10.1016/j.jad. 2017.09.031.

Dale, L. P., O'Hara, E. A., Schein, R., Inserra, L., Keen, J., Flores, M., \& Porges, S. W. (2011). Measures of infant behavioral and physiological state regulation predict 54-month behavior problems. Infant Mental Health Journal, 32(4), 473-486. https://doi. org/10.1002/imhj.20306. 
Enders, C. K., \& Bandalos, D. L. (2001). The relative performance of full information maximum likelihood estimation for missing data in structural equation models. Structural Equation Modeling, 8, 430-457. Retrieved from.

English, D. J., Graham, J. C., Litrownik, A. J., Everson, M., \& Bangdiwala, S. I. (2005). Defining maltreatment chronicity: Are there differences in child outcomes? Child Abuse \& Neglect, 29(5), 575-595. https://doi.org/10.1016/j.chiabu.2004.08.009.

English D. J., \& the LONGSCAN Investigators. (1997). Modified Maltreatment Classification System (MMCS). Retrieved from http://www.unc.edu/depts/sph/longscan/pages/maltx/mmcs/ LONGSCAN\%20MMCS\%Coding.pdf.

Éthier, L. S., Lemelin, J.-P., \& Lacharité, C. (2004). A longitudinal study of the effects of chronic maltreatment on children's behavioral and emotion problems. Child Abuse \& Neglect, 28(12), 1265-1278. https://doi.org/10.1016/j.chiabu.2004.07.006.

Finkelhor, D., Turner, H., Hamby Sewanee, S., \& Ormrod, R. (2011). Polyvictimization: Children's exposure to multiple types of violence, crime, and abuse. Free Inquiry in Creative. Sociology, $39,24-34$

Gabrielli, J., Jackson, Y., Tunno, A. M., \& Hambrick, E. P. (2017). The blind men and the elephant: Identification of a latent maltreatment construct for youth in foster care. Child Abuse and Neglect, 67, 98-108. https://doi.org/10.1016/j.chiabu. 2017.02.020

Graham, J. C., English, D. J., Litrownik, A. J., Thompson, R., Briggs, E. C., \& Bangdiwala, S. I. (2010). Maltreatment chronicity defined with reference to development: Extension of the social adaption outcomes findings to peer relations. Journal of Family Violence, 25, 311-324. https://doi.org/10.1007/ s10896-009-9293-9.

Graham, J. W. (2009). Missing data analysis: Making it work in the real world. Annual Review of Psychology, 60, 549-576. https:// doi.org/10.1146/annurev.psych.58.110405.085530

Grych, J. H., Wachsmuth-Schlaefer, T., \& Klockow, L. (2002). Interparental aggression and young children's representations of family relationships. Journal of Family Psychology, 16, 259-272.

Gusler, S., \& Jackson, Y. (2017). The role of poly-victimization in predicting differences in foster youths' appraisals. Child Abuse \& Neglect, 69, 223-231.

Guzder, J., Bond, S., Rabiau, M., Zelkowitz, P. \& Rohar, S. (2011). The Relationship between alliance, attachment and outcome in a child multi-modal treatment population: Pilot study. Journal of the Canadian Academy of Child and Adolescent Psychiatry, 20, 196-202. PMID: 21804848.

Hahm, H. C., Lee, Y., Ozonoff, A., \& Van Wert, M. J. (2010). The impact of multiple types of child maltreatment on subsequent risk behaviors among women during the transition from adolescence to young adulthood. Journal of Youth and Adolescence, 39, 528-540. https://doi.org/10.1007/s10964-009-9490-0.

Hambrick, E. P., Tunno, A. M., Gabrielli, J., Jackson, Y., \& Belz, C. (2014). Using multiple informants to assess child maltreatment: Concordance between case file and youth self-report. Journal of Aggression, Maltreatment \& Trauma, 23(7), 751-771. https://doi. org/10.1080/10926771.2014.933463.

Harpur, L. J., Polek, E., \& van Harmelen, A. (2015). The role of timing of maltreatment and child intelligence in pathways to low symptoms of depression and anxiety in adolescence. Child Abuse \& Neglect, 47, 24-37. https://doi.org/10.1016/j.chiabu. 2015.05.019.

Henneberger, A. K., Varga, S. M., Moudy, A. \& Tolan, P. H. (2016). Family functioning and high risk adolescents' aggressive behavior: Examining effects by ethnicity. Journal of Youth and Adolescence, 45, 145-155. https://doi.org/10.1007/s10964-0140222-8.
Herrenkohl, T. I., \& Herrenkohl, R. C. (2007). Examining the overlap and prediction of multiple forms of child maltreatment, stressors, and socioeconomic status: A longitudinal analysis of youth outcomes. Journal of Family Violence, 22, 553-562. https://doi.org/ 10.1007/s10896-0079107-x.

Hofmann, S. G., Asnaani, A., Vonk, I. J., Sawyer, A. T., \& Fang, A. (2012). The Efficacy of Cognitive Behavioral Therapy: A Review of Meta-analyses. Cognitive therapy and research, 36(5), 427-440. https://doi.org/10.1007/s10608-012-9476-1.

Jackson, Y., Gabrielli, J., Tunno, A. M. \& Hambrick, E. H. (2012) Strategies for longitudinal research with youth in foster care: Ademonstration of methods barriers and innovations. Children and Youth Services Review, 34, 1208-1213. https://doi.org/10. 1016/j.childyouth.2012.02.007.

Jaffee, S. R. (2017). Child maltreatment and risk for psychopathology in childhood and adulthood. Annual Review of Clinical Psychology, 13, 525-551. https://doi.org/10.1146/annurev-clinpsy032816-045005.

Jonson-Reid, M., Kohl, P. L., \& Drake, B. (2012). Child and adult outcomes of chronic child maltreatment. Pediatrics, 129(5), 839-845. https://doi.org/10.1542/peds.2011-2529.

Kline, P. (2011). Oaxaca-Blinder as a reweighting estimator. The American Economic Review, 532-537. https://doi.org/10.1257/a er.101.3.532.

LaFavor, T. \& \& Randall, J. In: Rambo, A., West, C., Schooley, A. \& Boyd, T. V. (eds) (2013). Multisystemic family therapy. Family therapy review: Contrasting contemporary models; family therapy review: Contrasting contemporary models. (Chapter xxxi, 277 Pages Retrieved from http://www2.lib.ku.edu/login?url= https://search-proquestcom.www2.lib.ku.edu/docview/ 1515988474 ? accountid $=14556$.

Lawrence, C. R., Carlson, E. A., \& Egeland, B. (2006). The impact of foster care on development. Development and Psychopathology, 18, 57-76. https://doi.org/10.1017/0S0954579406060044.

De Los Reyes, A. (2011). Introduction to the special section: More than measurement error: Discovering meaning behind informant discrepancies in clinical assessments of children and adolescents. Journal of Clinical Child and Adolescent Psychology, 40(1), 1-9. https://doi.org/10.1080/15374416.2011.533405.

De Los Reyes, A., \& Kazdin, A. E. (2005). Informant discrepancies in the assessment of childhood psychopathology: A critical review, theoretical framework, and recommendations for further study. Psychological Bulletin, 131(4), 483-509. https://doi.org/10.1037/ 0033-2909.131.4.483.

De Los Reyes, A., \& Ohannessian, C. M. (2016). Introduction to the special issue: Discrepancies in adolescent parent perceptions of the family and adolescent adjustment. Journal of Youth and Adolescence, 45(10), 1957-1972. https://doi.org/10.1007/ s10964-016-0533-z.

De Los Reyes, A., Lerner, M. D., Thomas, S. A., Daruwala, S., \& Goepel, K. (2013). Discrepancies between parent and adolescent beliefs about daily life topics and performance on an emotion recognition task. Journal of Abnormal Child Psychology, 41(6), 971-82. https://doi.org/10.1007/s10802-013-9733-0.

Lucia, V. C., \& Breslau, N. (2006). Family cohesion and children's behavior problems: A longitudinal investigation. Psychiatry Research, 141(2), 141-149. https://doi.org/10.1016/j.psychres. 2005.06.009.

MacKinnon, D. P., Lockwood, C. M., \& Williams, J. (2004). Confidence limits for the indirect effect: Distribution of the product and resampling methods. Multivariate Behavioral Research, 39 (1), 99-128. https://doi.org/10.1207/s15327906mbr39014.

Maschi, T., Morgen, K., Bradley, C., \& Hatcher, S. S. (2008). Exploring gender differences in internalizing behavior among maltreated youth: Implications for social work action. Child 
Adolescent Social Work Journal, 25, 531-547. https://doi.org/10. 1007/s10560-008-0139-8.

McCoy, H., McMillen, J. C., \& Spitznagel, E. L. (2008). Older youth leaving the foster care system: Who, what, when, where, and why? Child Youth Services Review, 30(7), 735-745. https://doi. org/10.1016/j.childyouth.2007.12.003.

Meyerson, L. A., Long, P. J., Miranda, Jr., R., \& Marx, B. P. (2002). The influence of childhood sexual abuse, physical abuse, family environment, and gender on psychological adjustment of adolescents. Child Abuse \& Neglect, 26, 387-405. https://doi.org/10. 1016/s0145-2134(02)00315-0.

Miller, G. E., Chen, E., \& Parker, K. J. (2011). Psychological stress in childhood and susceptibility to the chronic diseases of aging: Moving towards a model of behavioral and biological mechanisms. Psychological Bulletin, 137, 959-997. https://doi.org/10. 1037/a0024768.

Mills, R., Scott, J., Alati, R., O'Callaghan, M., Najman, J. M., \& Strathearn, L. (2013). Child maltreatment and adolescent mental health problems in a large birth cohort. Child Abuse \& Neglect, 37, 292-302. https://doi.org/10.1016/j.chiabu.2012.11.008.

Missouri Department of Social Services (2016) Children's Division Annual Report Fiscal Year 2016. Retrieved from http://dss. mo.gov/re/pdf/cs/2016-missouri-childrens-division-annualreport.pdf.

Moos, R., \& Moos, B. (1994). Family Environment Scale manual: Development, applications, research-Third edition. Palo Alto, CA: Consulting Psychologist Press.

Moriguchi, Y., Ohnishi, T., Lane, R. D., Maeda, M., Mori, T., Nemoto, K., \& Komaki, G. (2006). Impaired self awareness and theory of mind: An fMRI study of mentalizing in alexithymia. NeuroImage, 32(3), 1472-1482. https://doi.org/10.1016/j. neuroimage.2006.04.186.

Muthén, L. K., \& Muthén, B. O. (2010). Mplus User's Guide: Statistical Analysis with Latent Variables. Muthén \& Muthén.

Olson, D. H., Russell, C. S., \& Sprenkle, D. H. (1983). Circumplex model of marital and family systems: VI. Theoretical update. Family Process, 22, 69-83. https://doi.org/10.1111/j.15455300. 1983.00069.x.

Oshri, A., Topple, T. A., \& Carlson, M. W. (2017). Positive youth development and resilience: Growth patterns of social skills among youth investigated for maltreatment. Child Development, 88(4), 1087-1099. https://doi.org/10.1111/cdev.12865.

Owen, A. E., Thompson, M. P., Shaffer, A., Jackson, E. B., \& Kaslow, N. J. (2009). Family variables that mediate the relation between intimate partner violence and child adjustment. Journal of Family Violence, 24, 433-445. https://doi.org/10.1007/ s10896-009-9239-2.

Paivio, S. C., \& McCulloch, C. R. (2004). Alexithymia as a mediator between childhood trauma and self-injurious behaviors. Child Abuse \& Neglect, 28(3), 339-354. https://doi.org/10.1016/j.chia bu.2003.11.018

Pérez, J. C., Coo, S., \& Irarrázaval, M. (2018). Is maternal depression related to mother and adolescent reports of family functioning? Journal of Adolescence, 63, 129-141. https://doi.org/10.1016/j. adolescence.2017.12.013.

Pollastri, A., Epstein, L., Heath, G., \& Ablon, J. (2013). The collaborative problem-solving approach: Outcomes across settings. Harvard Review of Psychiatry, 21, 188-195. https://doi.org/10. 1097/HRP.0b013e3182961017.
Reinherz, H. Z., Giaconia, R. M., Paradis, A. D., Novero, C., \& Kerrigan, M. K. (2008). Health-promoting influences of the family on late adolescent functioning: $\mathrm{C} \& \mathrm{~A}$. Child \& Adolescent Social Work Journal, 25(6), 517-530. https://doi.org/10.1007/ s10560-008-0153-x.

Reynolds, C. R., \& Kamphaus, R. W. (2004). Behavior assessment system for children (2nd ed.): Manual. Circle Pines, MN: AGS Publishing.

Rogosch, F. A., Oshri, A., \& Cicchetti, D. (2010). From child maltreatment to adolescent cannabis abuse and dependence: A developmental cascade model. Development and Psychopathology, 22 (4), 883-897. https://doi.org/10.1017/S0954579410000520.

Rosnati, R., Iafrate, R., \& Scabini, E. (2007). Parent-adolescent communication in foster, inter-country adoptive, and biological Italian families: Gender and generational differences. International Journal of Psychology, 42(1), 36-45. https://doi.org/10. 1080/00207590500412128.

Sasser, J., Duprey, E. B., \& Oshri, A. (2019). A longitudinal investigation of protective factors for bereaved maltreated youth. Child Abuse \& Neglect, 96, 19 https://doi.org/10.1016/j.chiabu. 2019.104135.

Schermerhorn, A. C., Cummings, E. M., DeCarlo, C. A., \& Davies, P. T. (2007). Children's influence in the marital relationship. Journal of Family Psychology, 21, 259-269.

Schleider, J. L., \& Weisz, J. R. (2017). Family process and youth internalizing problems: A triadic model of etiology and intervention. Development and Psychopathology, 29(1), 273-301. https://doi.org/10.1017/S095457941600016X.

Simmel, C., Brooks, D., Barth, R. P., \& Hinshaw, S. P. (2001). Externalizing symptomatology among adoptive youth: Prevalence and preadoption risk factors. Journal of Abnormal Child Psychology, 29(1), 57-69. https://doi.org/10.1023/A: 1005251513130.

Stith, S. M., Liu, T., Davies, L. C., Boykin, E. L., Alder, M. C., Harris, J. M., \& Dees, J. E. M. E. G. (2009). Risk factors in child maltreatment: A meta-analytic review of the literature. Aggression and Violent Behavior, 14, 13-29. https://doi.org/10.1016/j. avb.2006.03.006.

Stone, K. J., Jackson, Y., Noser, A. E., \& Huffhines, L. (2020). Family environment characteristics and mental health outcomes for youth in foster care: Traditional and group-care placements. Journal of Family Violence, https://doi.org/10.1007/s10896-020-00177-x.

Tan, C. S. (2007). Test Review. [Review of the book Behavior assessment system for children (2nd ed.), by C. R. Reynolds \& R. W. Kamphaus]. Assessment for Effective Intervention, 32(2), 121-124. https://doi.org/10.1177/15345084070320020301.

Tung, I., Noroña, A. N., Lee, S. S., Langley, A. K., \& Waterman, J. M. (2018). Temperamental sensitivity to early maltreatment and later family cohesion for externalizing behaviors in youth adopted from foster care. Child Abuse \& Neglect, 76, 149-159. https://doi. org/10.1016/j.chiabu.2017.10.018.

Vanschoonlandt, F., Vanderfaeillie, J., Van Holen, F., De Maeyer, S., \& Robberechts, M. (2013). Externalizing problems in young foster children: Prevalence rates, predictors and service use. Children and Youth Services Review, 35(4), 716-724.

De Young, A. C., Kenardy, J. A., \& Cobham, V. E. (2011). Trauma in early childhood: A neglected population. Clinical Child and Family Psychology Review, 14(3), 231-250. https://doi.org/10. 1007/s10567-011-0094-3. 